\title{
Review of Research on Energy Conservation and Emission Reduction Technology Evaluation System in China
}

\author{
Jihui Sun ${ }^{1, a^{*}}$ and Xiufei Liang ${ }^{1, b}$ \\ ${ }^{1}$ School of Economics and Management, Dalian University, Dalian, China \\ adlsunjihui@163.com, b823475346@qq.com
}

Keywords: Energy saving and emission reduction; Technical evaluation; Index system; Evaluation model

\begin{abstract}
Based on the research of the literature in China, this paper expounds the present situation of the domestic energy saving and emission reduction technology evaluation system from two aspects of the construction of energy saving and emission reduction index system and the evaluation model, then the scholars have made a literature review, and the future research is prospected.
\end{abstract}

\section{Introduction}

The rise of energy saving and emission reduction is often referred to as the fourth industrial revolution. Since the "Energy-saving Emission Reduction" is put forward for the first time, energy saving and emission reduction has risen from a technical and economic development mode for political and strategic issues of national countries and regions in the world, attention to energy saving and emission reduction is closely related to the sustainable development, and the characteristics of "green" economy, circular economy and ecological civilization and more all over the world. Overall, the practice and theory of energy conservation and emission reduction in western countries are ahead of China. At present, the research on energy saving and emission reduction of domestic and foreign scholars mainly focus on the concept, connotation and implementation of energy-saving emission reduction path and so on, in the construction of quantitative index system, lack of relevant theoretical results.

\section{Energy-saving Emission Reduction Evaluation Index System}

Such index system includes many indexes of energy production, energy use, waste discharge and so on, can be roughly from the regions, industries and enterprises in three aspects in the research, constructs the evaluation index system of regional energy saving and emission reduction, the following research results of scholars has certain reference significance.

The construction of evaluation index system of regional energy saving and emission reduction can be divided into two aspects, the national and regional levels. At the national level, the National Bureau of statistics and the State Environmental Protection Administration were developed with the relevant departments to implement energy-saving emission reduction and statistical monitoring assessment scheme and measures to construct the evaluation index system, has important significance. Malin Song, Jie Yang (2008) from the macroscopic angle of domestic area as basic units to carry out energy-saving emission reduction performance evaluation, the classification of the indicators of energy saving and emission reduction from different angles, using the input-output efficiency evaluation of the energy-saving effect of different regions[1]. Yanpeng Wang (2009) based on the principle and basis of analysis index is established on the determination of the energy industry and key fields of consumption, energy efficiency and structure, industrial and agricultural water use and water saving, pollutant emissions, environmental quality in 5 aspects of 39 indicators and evaluation criteria, and constructs a set of index system of energy saving and emission reduction [2]. Qiang Mi and Juan Mi (2010) pointed out that the "11th Five-Year" China's energy consumption per unit of GDP index has many defects in its operation, by drawing on the experience of the domestic preparation of energy saving index system, China index system of energy conservation is established including the core index system and expansion index system of two 
parts, the index system for the macro index data acquired strong [3].

On the regional level, he and Dongfeng Huang (2006) based on the EISD of IAEA; determine the sustainable development of energy index system in Zhejiang province. Zhengfu Liu (2007) from the perspective of the impact of energy consumption, the 5 categories of 34 indicators: industrial structure, energy consumption structure index 9 index 4, the economic efficiency index of 8 , energy technical efficiency index 4 , total energy consumption per unit of economic indicators and lower rate of 9, constructs the evaluation index system of efficiency energy utilization in Fujian province [4]. Kedong Yin (2010) in Shandong Province as the research object, the 17 cities of Shandong Province, the level of energy conservation and emission reduction as a comprehensive measure of research, and the level of energy conservation and emission reduction in various regions of the classification and dynamic evaluation [5]. Juan Lv, Congcong Liu (2012) according to Heilongjiang province from 2001 to 2010 ten years of the first industry, the proportion of the second industry and the proportion of the third industry, the construction of the evaluation index system for Heilongjiang province [6].

\section{Evaluation Model of Energy Saving and Emission Reduction}

According to the relevant research results, the domestic scholars have different theoretical models and mathematical evaluation models to study the different theories and mathematical models.

Data Envelopment (DEA) Evaluation Method. Mingmin Li (2013) using the DEA model, in the energy consumption as a non-expected output, energy consumption as the input of two kinds of constraints, the thirty provinces of the country's energy saving and emission reduction efficiency of the system analysis [7]. Pengfei Yu, Yue Li, Min Duo (2010) will be energy, water consumption and environmental capacity resources in three areas to construct the input indicators, using the extended DEA model is the super efficiency DEA model to calculate the relative efficiency of energy saving and emission reduction in thirty-one provinces and cities nationwide, the value of the corresponding value of the economies of scale and economies of scale value is increased or reduction [8]. Zhonghua Wang and Huizhu Liang (2012) using DEA model to get the comprehensive technical efficiency, pure technical efficiency and scale efficiency of energy saving and emission reduction in 20 industrial sectors in Heilongjiang province and the correlation analysis [9].

Fuzzy Comprehensive Evaluation Method. Herui Cui, Jing Ge (2012) in the index system was established based on the energy saving and emission reduction in Hebei Province, the weight of each index was determined by entropy method, combining the fuzzy evaluation model of the evaluation and research of energy saving and emission reduction in Hebei province from 2006 to 2010 [10]. Cuilian Liu, Jianmei Liu, Qi Li (2012), the use of expert evaluation method and AHP method to establish the index system, then using fuzzy evaluation method, finally through the empirical proof of Qingdao port of Qingdao port has obvious advantages in operating personnel technical training, special organization construction and improvement, new technologies and new products as well as the number of the production of integrated energy consumption management etc. [11]. Jinlou Zhao, Gen Li, Qi Su (2012), from the physical affair, one of three levels of structure of shipbuilding enterprises energy saving evaluation index system, and using DEMATEL repeatedly revision of the initial weights, the comprehensive evaluation of improved AHP combined with fuzzy comprehensive evaluation method of the model. The Jinzhao Jin (2010) an evaluation matrix obtained by membership function and expert scoring method, establishes the evaluation system model of fuzzy mathematics, and a chemical enterprise as an example of the fuzzy evaluation of the enterprise energy saving and emission reduction performance, provide a quantitative assessment for the enterprise energy saving and emission reduction work reference.

Grey Theory Evaluation Method. Wei Xu, Yonghong Wang, Bing Song (2013) first energy-saving emission reduction index, including index, energy index of three parts, energy saving and emission reduction evaluation index framework is established, and then introduces the principle and method of grey correlation analysis and five detailed steps, finally, an operator group company two branch an example, evaluation of the two branch of energy saving and emission reduction performance for the strength evaluation index framework and grey correlation analysis method [12]. 
Caiqing Zhang, Yuanyuan Dong (2010) in energy saving and emission reduction from 1996 to 2007 9 related taxes based on the data by using the gray relational model, study the relationship between tax and energy saving and emission reduction, we obtained four conclusions and specifically explained. Juan Lv, Congcong Liu (2012) on the evolution of industrial structure on energy saving and emission reduction contribution as the goal, the use of compositional data analysis theory, Logratio transform formula calculated from 2011 to 2020 ten years the proportion of the first industry, the second industry and the third industry, and by 2011 the proportion of three industries to verify the validation results show that this model can be used effectively to predict the three industrial structure [13].

Principal Component Analysis and Evaluation Method. Shijin Wang (2013) constructs the enterprise energy saving and emission reduction evaluation index system, through the listed coal enterprise's empirical research, using the principal component analysis method to calculate the corresponding total score of each enterprise [14]. Fang Zhou, Jia Shi (2012) used questionnaire and face-to-face interviews, the sample D data of 68 companies, analysis of energy saving and emission reduction behavior of enterprises are analyzed and the quantitative interpretation of the principal component, finally got three corresponding conclusions and recommendations. Lin Yang, Ying Wang (2011) in constructing index framework, using the SPSS feature selection value is greater than 1 , the variance decomposition analysis using the maximum variance method to extract the principal components, according to the results of principal component analysis, combined with the related tax policy, puts forward some measures for energy saving and emission reduction in the countermeasures and suggestions [15]. Wu Qiang, Chunyou Wu (2009) making energy efficiency evaluation index system, and on the basis of this index system, construct the environment of energy economic efficiency and energy efficiency evaluation index system, the six indicators of pollutant reduction as an index by principal component analysis, finally using the DEA model, the calculation of package thirty-one provinces of the value of energy efficiency, energy efficiency, energy value of environmental efficiency by using DEA software.

\section{Literature Review and Research Prospects}

Literature Review. The scholars have put forward a more comprehensive and specific energy-saving emission reduction technology evaluation index system and gives the corresponding weight of each index, which provides a method of path and research method, comprehensive evaluation index system for Liaoning province to build energy-saving emission reduction at the same time, the study also exist some deficiencies, which will become the future research direction.

Research Prospects. From the construction of energy-saving emission reduction index system point of view, to study more macro policy, the index system is relatively perfect, according to the special area to establish the evaluation index system of less appropriate energy saving technology. The weights of different indexes are scientific, reasonable and practical. On the evaluation method of model construction, the mathematical model of their inherent defects, the nature of possible reaction of the problem can't be complete and scientific, the subjective model, even if the same research topic due to the different causes of the adopted mathematical model results may be completely different.

In the future, we should pay attention to the function of index system evaluation, and further improve the function of index system and decision-making, and provide theoretical support and practical guidance for regional economic development. In the process of building energy saving and emission reduction evaluation index system, the evaluation criteria of the indicators are further defined. In order to overcome the defect of subjective weighting, the information entropy and its mathematical properties can be introduced into the model of uncertainty measure.

\section{References}

[1] M.L Lin and J Yang: Resource Development and Market, (2008) No.24, p.32-33. (In Chinese) 
[2] Y.P Wang: Coal Economic Research, (2009) No.02, p.31-32. (In Chinese)

[3] Q Mi and J Mi: Ecological Economy, (2010) No.02, p.58-61. (In Chinese)

[4] Z.F Liu: Energy and Environment, (2004) No.04, p.2-4. (In Chinese)

[5] K.D Yin and B Wang: Scientific and technological progress and Countermeasures, (2010) No.22, p.172-176. (In Chinese)

[6] J Lv and C.C Liu: Environmental Science and Management, (2012) No.05, p.41-43. (In Chinese)

[7] M.M Li: Statistics and Decision, (2013) No.18, p.126-130. (In Chinese)

[8] P.F Yu, Y Li and M Du: Environmental Science and Management, (2010) No.35, p.13-20. (In Chinese)

[9] Z.H Wang and H.T Liang: Forestry Economy in China, (2012) No.02, p.39-42. (In Chinese)

[10]H.R Cui and J Ge: Journal of Electric Power, (2012) No.05, p.484-489. (In Chinese)

[11]C.L Liu, Q Li and J.M Liu: Waterway Engineering, (2012) No.04, p.80-97. (In Chinese)

[12] W Xu, Y.H Wang and B Song: Journal of College of Arts and Sciences, (2013) No.16, p.89-92. (In Chinese)

[13]C.Q Zhang and Y.Y Dong: East China Power, (2010) No.08, p.1123-1125. (In Chinese)

[14]Q.S Wang: Statistical Research, (1994) No.01, p.57-61. (In Chinese)

[15]L Yang and Y Wang: Financial Research, (2011) No.03, p.14-17. (In Chinese) 